\title{
Rest Cannot Always Recover the Dynamic Properties of Fatigue-Loaded Intervertebral Disc
}

\author{
Jaw-Lin Wang, PhD, ${ }^{*}$ Tai-Kuan Wu, BS, ${ }^{*}$ Tzu-Cheng Lin, BS, ${ }^{*}$ Chih-Hsiuch Cheng, PT, \\ and Shyh-Chin Huang, PhD†
}

Study Design. An in vitro biomechanical study using adolescent porcine discs.

Objective. To find the effect of fatigue loading and rest on the dynamic properties of healthy intervertebral disc.

Summary of Background Data. The fatigue loading is a risk factor for low back pain. The disc dynamic properties describe the shock attenuation capability of disc. Knowledge of effect of fatigue loading and rest on the disc dynamic properties can be beneficial for the study of fatigue loading induced spinal disorder.

Methods. Specimens were divided into short-term $(0.5$ hours at $5 \mathrm{~Hz}, \mathrm{n}=9$ ) and long-term (2 hours at $5 \mathrm{~Hz}, \mathrm{n}=$ 9) fatigue loading groups. The specimen was applied with fatigue loading, followed by a 12-hours rest, and then applied with the second fatigue loading again. The impulse loading was applied at $0,10,20$, and 30 minutes during short-term group and at $0,0.5,1$, and 2 hours during long-term group using a drop-tower apparatus. The stiffness, damping coefficient, and ratio were calculated using impulse loading information. Dynamic properties between first and second fatigue loading were compared.

Results. The stiffness increased, but the damping coefficient and ratio decreased with fatigue loadings. A 12hours rest can fully restore the dynamic properties of fatigue loaded disc to original status. However, the degradation of dynamic properties during the subsequent fatigue loading was faster than the previous fatigue loading if the disc experienced a long-term fatigue loading.

Conclusion. A 12-hours rest can largely restore disc dynamic properties during fatigue loading; hence fully recover disc dynamic properties. A long-term fatigue loading squeezes the disc fluid and injures the disc integrity. The 12-hours rest can recover the fluid loss but not the injury of disc. Hence, the disc degradation during the second fatigue loading was faster than the first fatigue loading.

Key words: disc, stiffness, damping coefficient, damping ratio, impulse loading, fatigue. Spine 2008;33:1863-1869

From the "Institute of Biomedical Engineering, National Taiwan University, and +Department of Mechanical Engineering, National Taiwan University of Science and Technology, Taipei, Taiwan.

Supported by the National Science Council, Taiwan (NSC 95-2221-E002-031) and National Health Research Institute, Taiwan (NHRIEX96-9425EI).

Acknowledgment date: December 11, 2007. Acceptance date: March 17, 2008.

The manuscript submitted does not contain information about medical device(s)/drug(s).

Foundation funds were received in support of this work. No benefits in any form have been or will be received from a commercial party related directly or indirectly to the subject of this manuscript.

Address correspondence and reprint requests to Jaw-Lin Wang, PhD, Professor, \#1, Section 1, Jen-Ai Road, Institute of Biomedical Engineering, College of Engineering \& College of Medicine, National Taiwan University, Taipei 10051, Taiwan, Republic of China; E-mail: jlwang@ntu.edu.tw
Epidemiologic studies have suggested highly repetitive activities as a risk factor for low back pain. ${ }^{1,2}$ Occupations that require higher cumulative spinal compression often led to low back pain problems. ${ }^{3}$ The fatigue loading due to exposure to whole body vibration has also been pointed out as a risk factor for occupational low back disorders. ${ }^{4,5}$ The safe limits of repetitive activities and whole body vibration that prevent spinal disease are, however, not reliably defined, and the consequences of disc function following fatigue loading are also not clearly understood.

The mechanism of fatigue failure is a complex process, leading to the acceleration of the degenerative processes and development of low back disorders. The failure can be observed primarily at the vertebral body and endplate because of axial compressive cyclic loading ${ }^{2,6,7}$; at the anulus fibrosus because of flexion cyclic loading ${ }^{8}$; and at the endplate, facet, anulus fibrosus, and capsular ligament because of torsion fatigue loading. ${ }^{9}$ The failure would also lead to disc protrusion due to frequent bending and lifting in living people. ${ }^{10,11}$ During the submaximal cyclic loading, microfailures may be generated ${ }^{12}$ and lead to spinal instability, which is frequently observed in chronic patient with low back pain. ${ }^{6}$ Most of the mechanisms of above-mentioned motion segment failures are directly or indirectly related to the degeneration ${ }^{13-15}$ or treatment ${ }^{16}$ of disc.

The disc is a structure of a nucleus pulposus surrounded by anulus fibrosus and endplate, and the dynamic properties of disc depend on the degree of disc hydration and integrity. ${ }^{17}$ During the fatigue loading, the fluid of disc is squeezed out and the disc may be injured. The rest can restore the fluid content of disc, but may not be able to heal the disc in short time. The inequality of fatigue loading or rest may be the reason that both reversible and irreversible changes of disc mechanical properties following fatigue loading were reported in literature (Table 1). ${ }^{18-23}$ The quantitative links of dynamic properties of disc (including the stiffness and damping coefficient of disc and damping ratio of disc construct) following fatigue loading and rest recovery were not conclusively determined yet. The objective of this study is to find this links and mechanism of disc degradation following fatigue loading.

\section{- Materials and Methods}

\section{Specimen Preparation}

Fresh vertebral body-disc-vertebral body specimens (L1-L2, L3-L4) of 6-month-old swine were obtained immediately after 
Table 1. Studies of Effect of Fatigue Loading and Rest Recovery on Disc Mechanical Properties

\begin{tabular}{|c|c|c|c|c|c|c|}
\hline & $\begin{array}{l}\text { Loading } \\
\text { Type }\end{array}$ & Subject & $\begin{array}{c}\text { Loading Period, Magnitude, } \\
\text { and Frequency }\end{array}$ & Rest Time & Measurements & Recovery \\
\hline $\begin{array}{l}\text { Ekstrom et al } \\
{ }_{1996^{18}}\end{array}$ & Dynamic & Pig & $\begin{array}{l}1 \mathrm{~h}, 50 \mathrm{~N}, 5 \mathrm{~Hz} \text { and } 1 \mathrm{~h}, \\
100 \mathrm{~N}, 5 \mathrm{~Hz}\end{array}$ & $1 \mathrm{~h}$ & Deformation & No \\
\hline $\begin{array}{l}\text { Johanessen et al } \\
2004^{19}\end{array}$ & Dynamic & Sheep & $2.7 \mathrm{~h}, 50$ to $400 \mathrm{~N}, 1 \mathrm{~Hz}$ & $18 \mathrm{~h}$ & $\begin{array}{l}\text { Stress relaxation and } \\
\text { stiffness }\end{array}$ & Yes \\
\hline $\begin{array}{l}\text { Van der veen et al } \\
\quad 2005^{20}\end{array}$ & Static & Pig & Three $0.25 \mathrm{~h}, 2 \mathrm{MPa}$ & $\begin{array}{l}\text { Three } 0.5 \mathrm{~h} \text { at } 0.025 \\
\mathrm{MPa}\end{array}$ & $\begin{array}{l}\text { Deformation and } \\
\text { pressure }\end{array}$ & No \\
\hline $\begin{array}{l}\text { Vresilovic et al } \\
2006^{21}\end{array}$ & Dynamic & Sheep & $2.7 \mathrm{~h}, 50$ to $400 \mathrm{~N}, 1 \mathrm{~Hz}$ & $18 \mathrm{~h}$ & Stress relaxation & $\begin{array}{l}\text { No (nucleus } \\
\text { removed) }\end{array}$ \\
\hline $\begin{array}{l}\text { Van der Veen et al } \\
\quad 2007^{22}\end{array}$ & $\begin{array}{l}\text { Static and } \\
\text { dynamic }\end{array}$ & Goat & Four $0.25 \mathrm{~h}, 2 \mathrm{Mpa}$ & $\begin{array}{l}\text { Three } 0.5 \mathrm{~h} \text { plus } 10 \mathrm{~h} \\
\text { at } 20 \mathrm{~N}\end{array}$ & Deformation and stiffness & Yes \\
\hline $\begin{array}{l}\text { MacLean et al } \\
2007^{23}\end{array}$ & Static & Rat & $\begin{array}{l}4 \mathrm{~h}, 0.2 \mathrm{MPa} \text { and } 4 \mathrm{~h}, 1.0 \\
\mathrm{MPa}\end{array}$ & Two $6 \mathrm{~h}$ at $0.04 \mathrm{MPa}$ & Deformation & No \\
\hline
\end{tabular}

death. Each specimen was carefully cleaned of muscle tissue. The posterior process and facet joint were also removed. The specimens were mounted at both ends, i.e., the proximal half of cranial vertebra and the distal half of caudal vertebra, using quick setting epoxy. The specimens were placed in double plastic bags and frozen at $-20^{\circ} \mathrm{C}$ for storage. Before experiments, the specimens were removed from freezer and kept in room temperature for at least 6 hours, which is sufficient to fully defrost the disc. The specimens were wrapped with gauze and saline during the defrosting period. All discs were rated Grade 1 according to criteria defined by Galante. ${ }^{24}$ The size of tested porcine disc was similar to the size of human lumbar disc (Table 2). ${ }^{25-27}$

\section{Impulse Testing Apparatus and Protocol}

A "drop-tower type" testing apparatus was used for impulse testing (Figure 1). The impulse energy was generated by the free fall of impactor and was transmitted to the specimen through the impounder. The shock absorber was placed on top of the impounder to control the impulse contact period. The contact period is the time interval that impactor compresses the impounder before it bounces back. The shock absorbers were designed to give the contact periods at level of 20 milliseconds. ${ }^{28}$ The specimen was mounted vertically below a uniaxial load cell (STC-500 kg, Vishay Intertechnology, Inc., Malvern, PA). The measured force was the resultant force due to impulse energy. The displacement of the specimen was measured using a linear potentiometer (25 mm, Gefran Inc., Italy). A highspeed data acquisition card (PCI-6071E, National Instrument, Inc., Austin, TX) was used to record the signals of force and displacement. Half seconds data were recorded at $10 \mathrm{kHz}$ sam-

Table 2. Dimensions (mm) of Human and Porcine Lumbar Discs

\begin{tabular}{|c|c|c|}
\hline & $\begin{array}{l}\text { Porcine Lumbar Disc } \\
\text { of Current Study }\end{array}$ & $\begin{array}{l}\text { Human Lumbar Disc } \\
\text { in Literature }\end{array}$ \\
\hline Disc height & $7.0(0.8)$ & $10.7(0.5),{ }^{25} 8.9(0.11)^{26}$ \\
\hline Disc width & $36.5(1.8)$ & $\begin{aligned}{ }^{*} E P \_W u & =44.4(2.6)^{27} \\
{ }^{*} E P \_W l & =47.1(2.7)^{27}\end{aligned}$ \\
\hline Disc depth & $24.9(1.0)$ & $\begin{aligned}{ }^{*} E P \_D u & =34.8(0.5)^{27} \\
{ }^{*} E P \_D I & =34.4(0.9)^{27}\end{aligned}$ \\
\hline
\end{tabular}

Data is mean (standard deviation).

* Data is based on the measurement of endplate.

EP_Wu indicates upper endplate width; EP_WI, lower endplate width; EP_Du, upper endplate depth; EP_DI, lower endplate depth. pling rate. The signals were low-pass filtered at $500 \mathrm{~Hz}$ frequency using Butterworth filtering algorithm. The impulse weight was $12 \mathrm{~kg}$ and the impulse height was $1 \mathrm{~cm}$, which resulted in $1.2 \mathrm{~J}$ impulse energy. The averaged peak loading during impulse was $1200 \mathrm{~N}$. The force required to injury porcine disc was less studied, but since the peak compressive load of the human spine was greater than $8600 \mathrm{~N}$ in blocking maneuvers during football linemen, ${ }^{29} 17,000 \mathrm{~N}$ in weight lifters, ${ }^{30}$ and $5500 \mathrm{~N}$ in tricked fall, ${ }^{31}$ and the strength of porcine disc is generally stronger than human one, the damage of porcine disc due to impulse loading was minimal.

\section{Fatigue Loading Apparatus and Protocol}

A vibrator composed of 2 eccentric rotors and 1 motor was mounted into the impactor of the impulse testing apparatus to create the fatigue loading. The fatigue loading was produced by the rotation of 2 counter-rotated eccentric rotors driven by a motor. The vibration was transmitted to the specimen through the impounder (Figure 1). ${ }^{32}$ The root mean squared averaged axial loading of cyclic loading was $420 \mathrm{~N}$ (peak to peak; $190-$ $590 \mathrm{~N}$ ). The magnitude of fatigue loading was kept constant through out the study. The loading frequency was $5 \mathrm{~Hz}$. Eighteen specimens were used. The specimens were divided into short-term (0.5 hours, 9000 cycles, $\mathrm{n}=9$ ) and long-term (2 hours, 36,000 cycles, $\mathrm{n}=9$ ) fatigue loading groups. In the short-term fatigue loading group, the specimen was loaded with 0.5 hours fatigue loading, followed by a 12 -hours rest, and then applied with the second 0.5 hours fatigue loading again. During the fatigue loadings, a $1.2 \mathrm{~J}$ impulse loading was applied periodically on the specimen at 10 minutes interval. In the long-term fatigue loading group, the specimen was loaded with 2 hours fatigue loading first, followed by a 12-hours rest, and then applied with the second 2 hours fatigue loading again. During the fatigue loading, the impulse loading was applied at 0, 0.5, 1, and 2 hours (Figure 2). The specimen was wrapped with saline-soaked gauze and sprayed constantly with saline through out the fatigue loading to prevent the disc from dehydration. During the rest recovery, the specimen was immersed in $5^{\circ} \mathrm{C}$ physiologic concentration saline bath.

\section{Mathematical Model and Data Analysis}

A one degree of freedom vibration system (Figure 1) was used to simulate the dynamic behavior of disc as follows.

$$
M \ddot{\mathrm{x}}+C \dot{\mathrm{x}}+K \mathrm{x}=0
$$


Figure 1. Impulse testing apparatus and fatigue testing module. The impulse energy, generated by the free fall of the impactor, was transmitted to the specimen through impounder. The fatigue loading was generated by the vibrator, which is composed of 2 counter-rotated eccentric rotors.

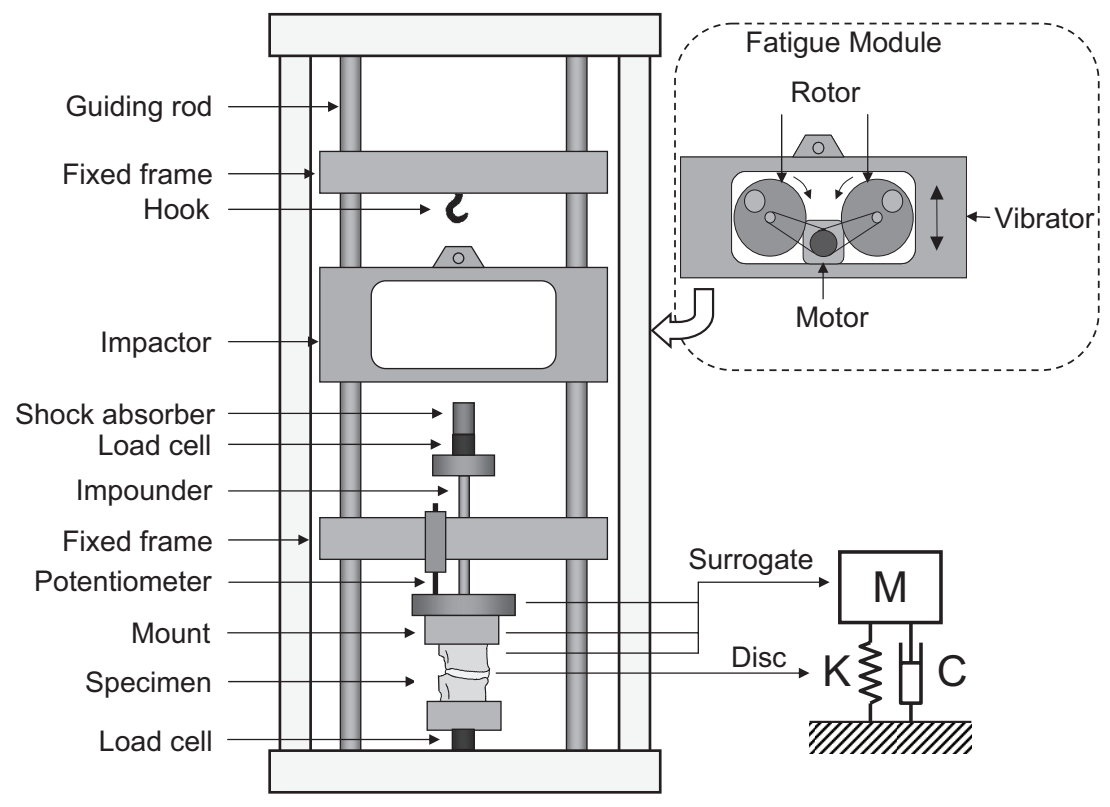

The system is composed of a mass, spring, and damper. The mass $(M)$ is the weight of surrogate including the upper vertebra, mount, and impounder jig (9 $\mathrm{kg}$ in total). The spring stiffness $(K, \mathrm{~N} / \mathrm{mm})$ and damping coefficient ( $C$, Ns/ $\mathrm{mm}$ ) of intervertebral disc, and the damping ratio $(\xi)$ of the disc construct (disc with surrogate) can be calculated by the displacement curve of impulse history. The impulse loading of the specimen generated the first peak. After the impulse loading, the specimen was at the phase of free vibration, which generating the second and third peaks (Figure 3). The $K, \xi$, and $C$ can be calculated by the displacement $\left(x_{1}\right.$ and $\left.x_{2}\right)$ and the time period $\left(\tau_{\mathrm{d}}\right)$ between the second and third peaks using the following equations. ${ }^{33}$

$$
\begin{aligned}
& K=M\left(\frac{2 \pi}{\tau_{\mathrm{d}}}\right)^{2} \\
& \xi=\frac{1}{2 \pi} \ln \frac{x_{1}}{x_{2}} \\
& C=2 \xi \sqrt{K M}
\end{aligned}
$$

\section{Short Term Fatigue Protocol}

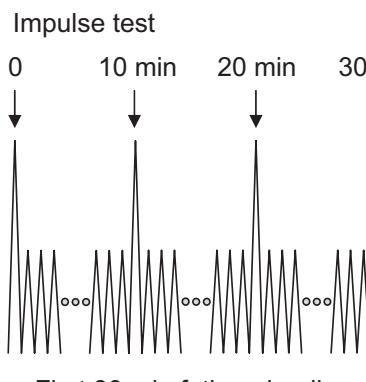

First 30 min fatigue loading
Impulse test

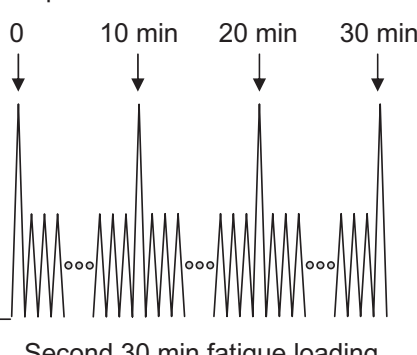

$12 \mathrm{hr}$ rest

Long Term Fatigue Protocol

Impulse test

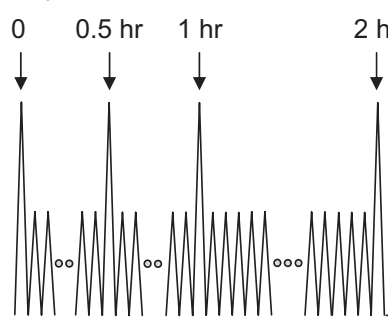

First 2 hr fatigue loading
12 hr rest

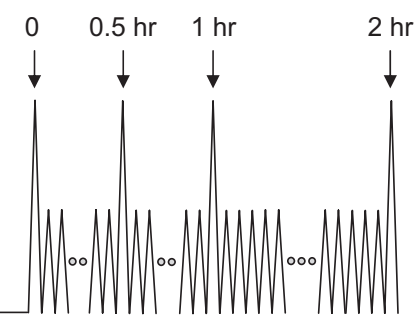

Second $2 \mathrm{hr}$ fatigue loading
Figure 2. Loading protocol. During the short-term fatigue loading, the specimen was loaded with 0.5 hours fatigue loading, followed by a 12-hours rest, and then the second 0.5 hours fatigue loading. During the fatigue loadings, a $1.2 \mathrm{~J}$ impulse loading was applied periodically on the specimen at 10 minutes interval. During the long-term fatigue loading, the specimen was loaded with 2 hours fatigue loading first, followed by a 12-hours rest, and then the second 2 hours fatigue loading. During the fatigue loading, the specimen was the impulse loading was applied at 0 , $0.5,1$, and 2 hours. 


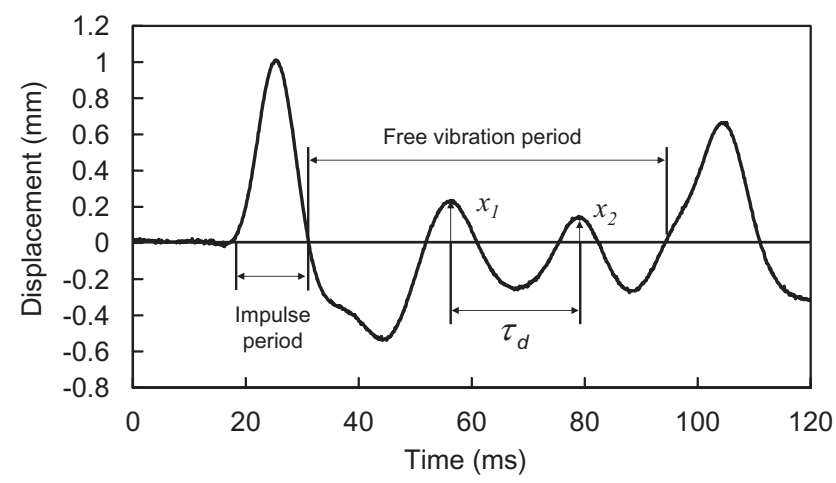

Figure 3. A typical displacement curve of the specimen during an impulse loading. The impulse loading generated the first peak displacement. After the impulse loading, the specimen was at the phase of free vibration, which generating the second and third peaks. The displacement $\left(x_{1}\right.$ and $\left.x_{2}\right)$ and the time period $\left(\tau_{d}\right)$ between the second and third peaks are used to calculate the stiffness $(K)$, damping coefficient $(C)$, and damping ratio $(\xi)$.

It should be noted that the damping ratio $(\xi)$ is also a function of surrogate mass $(M)$ and disc stiffness $(K)$ and damping coefficient $(C)(\xi=C / 2 \sqrt{K M})$.

\section{Statistical Analysis}

The spring stiffness $(K, \mathrm{~N} / \mathrm{mm})$ and damping coefficient $(C$, $\mathrm{Ns} / \mathrm{mm}$ ) of intervertebral disc, and the damping ratio $(\xi)$ of the disc construct between first and second fatigue loading were compared using dependent $t$ test. Each test was considered significant at $P<0.05$.

\section{Results}

The averaged stiffness of intact discs was 781 (SD: 58) $\mathrm{N} / \mathrm{mm}$, and the damping coefficient was 0.65 (SD: 0.08) $\mathrm{Ns} / \mathrm{mm}$. The damping ratio of intact disc construct was 0.123 (SD: 0.015). In the end of the second long-term fatigue loading, which can be considered as the steady state, the stiffness increased to 1010 (SD: 34) N/mm, the damping coefficient decreased to 0.42 (SD: 0.04) Ns/mm and the damping ratio decreased to 0.069 (SD: 0.007).

During the first short-term (0.5 hours) fatigue loading, the stiffness increased from 783 (SD: 48) N/mm to 924 (SD: 30$) \mathrm{N} / \mathrm{mm}(P=0.000)$. The damping coefficient decreased from 0.68 (SD: 0.05$) \mathrm{Ns} / \mathrm{mm}$ to 0.55 (SD: $0.05) \mathrm{Ns} / \mathrm{mm}(P=0.000)$. The damping ratio decreased from 0.128 (SD: 0.010$)$ to 0.095 (SD: 0.008) $(P=$ $0.000)$. After 12-hours rest, the stiffness recovered to 771 (SD: 51 ) $\mathrm{N} / \mathrm{mm}$, the damping coefficient recovered to 0.67 (SD: 0.04 ) Ns/mm, and the damping ratio recovered to 0.126 (SD: 0.006$)$. At the end of second fatigue loading, the stiffness increased to 928 (SD: 34) N/mm, the damping coefficient decreased to 0.55 (SD: 0.08) Ns/mm, and the damping ratio decreased to 0.095 (SD: 0.014). The stiffness, damping coefficient, and damping ratio of same intervals (0 10, 20, and 30 minutes) all showed no statistically differences between first and second fatigue loading (all $P>0.05$ ) (Figure 4).

During the first long-term ( 2 hours) fatigue loading, the stiffness increased from 767 (SD: 62) N/mm to 1018 (SD: 54$) \mathrm{N} / \mathrm{mm}$ in 1 hour $(P=0.000)$. The increase of प1st fatigue loading

口2nd fatigue loading
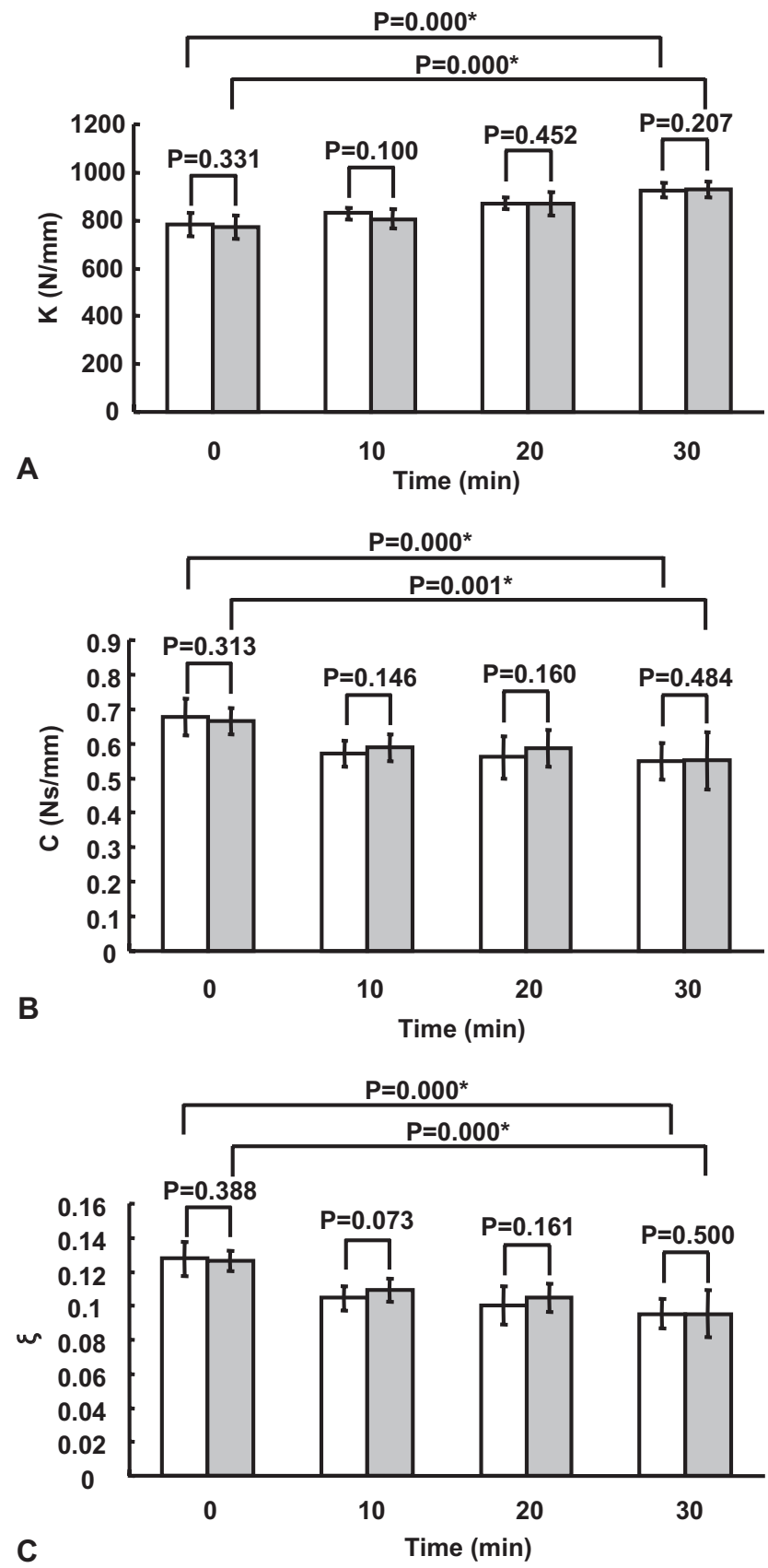

Figure 4. The stiffness $(K)$, damping coefficient $(C)$, and damping ratio $(\xi)$ as a function of loading history during the short-term $(0.5$ hours) fatigue loading.

stiffness from 1 hour to 2 hours is not statistically significant $(P=0.219)$. After 12 -hours rest, the stiffness recovered to 803 (SD: 70) N/mm, which is not statistically different from the original status of first fatigue loading. During the second fatigue loading, the stiffness reached steady state $(1017 \mathrm{~N} / \mathrm{mm})$ in 0.5 hours. The increase of stiffness from 0.5 to 2 hours is not statistically significant $(P=0.301)$. Comparing the stiffness history curve of the 2 fatigue loading, the stiffness of second fatigue loading at 0.5 hours is significantly higher than the one of first 
fatigue loading at 0.5 hours, whereas the stiffness of other time intervals ( 0,1 , and 2 hours) between 2 fatigue loading showed no statistically differences (all $P>0.05$ ) (Figure 5A).

The damping coefficient decreased from 0.63 (SD: 0.10 ) $\mathrm{Ns} / \mathrm{mm}$ to 0.42 (SD: 0.09 ) Ns/mm in 1 hour during

$\square$ 1st fatigue loading

$\square$ 2nd fatigue loading
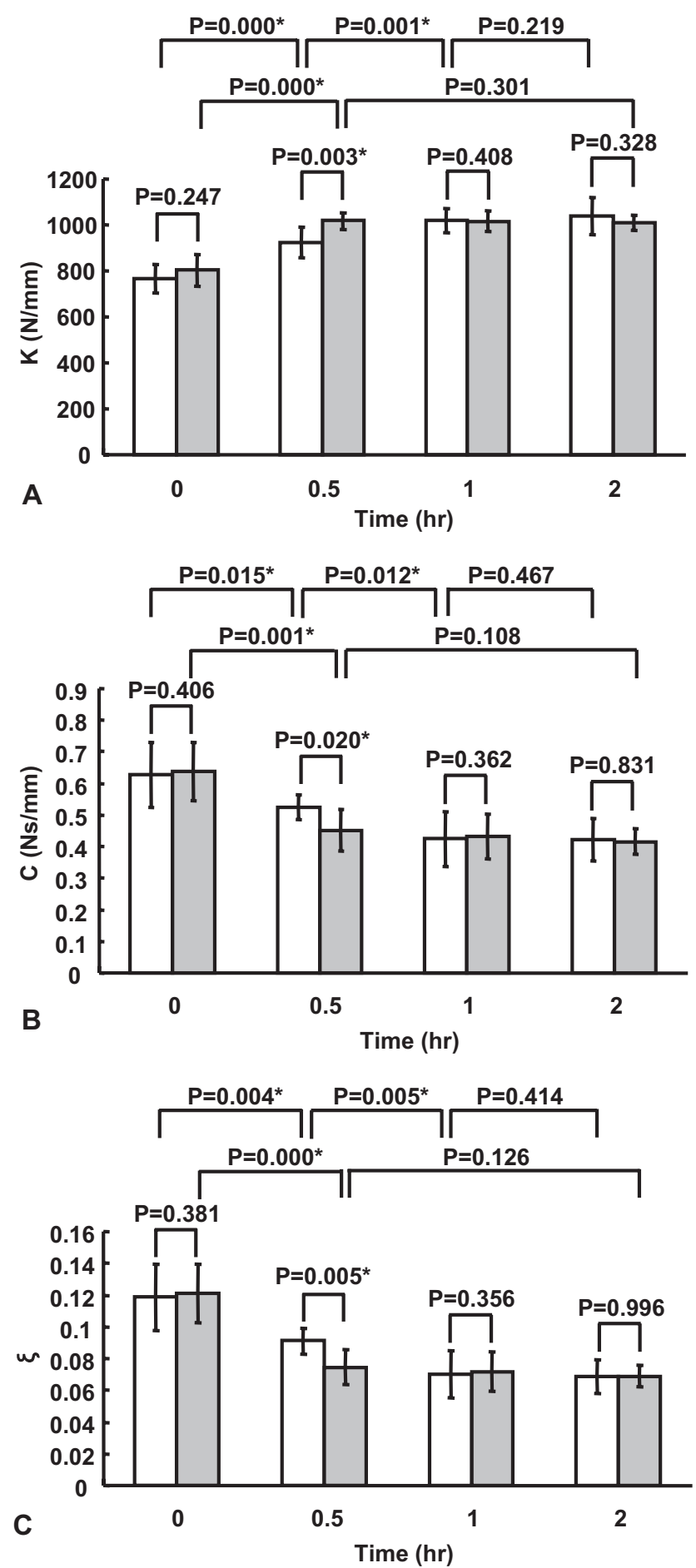

Figure 5 . The stiffness $(K)$, damping coefficient $(C)$, and damping ratio $(\xi)$ as a function of loading history during the long-term (2 hours) fatigue loading. the first long-term fatigue loading. The decrease of damping coefficient from 1 hour to 2 hours is not statistically significant $(P=0.467)$. After 12 -hours rest, the damping coefficient recovered to 0.64 (SD: 0.09) Ns/mm. The damping coefficient decreased to 0.45 (SD: 0.06) $\mathrm{Ns} / \mathrm{mm}$ in 0.5 hours. The decrease of damping coefficient from 0.5 to 2 hours is not statistically significant $(P=$ 0.108) (Figure 5B).

The damping ratio decreased from 0.119 (SD: 0.021) to 0.070 (SD: 0.015 ) in 1 hour during the first long-term fatigue loading. The decrease of damping coefficient from 1 hour to 2 hours is not statistically significant $(P=$ $0.414)$. After 12 -hours rest, the damping ratio recovered to 0.121 (SD: 0.018 ). The damping ratio decreased to 0.075 (SD: 0.011 ) in 0.5 hours. The decrease of damping ratio from 0.5 to 2 hours is not statistically significant $(P=0.126)$ (Figure 5C).

Comparing the damping properties (including coefficient and ratio) history curve of the first and second fatigue loading, the damping properties of second fatigue loading at 0.5 hours is significantly lower than the one of first fatigue loading at 0.5 hours (damping coefficient, $P=0.020$; and damping ratio, $P=0.005$ ), whereas the damping properties at other time intervals $(0,1$, and 2 hours) between 2 fatigue loading showed no statistically differences (all $P>0.05$ ).

\section{Discussion}

The mechanical disc functions such as sustaining external loading and attenuating impulse loading is provided by the mechanical interaction of anulus fibrosus, endplate, and nucleus pulposus. The fluid content and disc integrity are the 2 major roles in maintaining the disc mechanical functions. Our study found that 12-hours saline bath rest can recover the disc dynamic properties. This may suggest that the saline bath can recover the fluid loss during fatigue loading, hence restoring stiffness and damping properties to the beginning of fatigue loading. The recovery of stiffness was also reported in human and sheep spine motion segments. ${ }^{34,35}$

In the test of long-term fatigue loading, the stiffness and damping properties reached steady state in 1 hour during the first fatigue loading, but in 0.5 hours during the second fatigue loading. It was speculated that the annular fibrosus or endplate was damaged during the first fatigue loading, causing the fluid to flow out the disc more rapidly during the second fatigue loading. In the test of the short-term fatigue loading, the disc was not damaged, hence the degradation of stiffness and damping properties remained similar between first and second fatigue loading. This may explain why the in vitro biomechanical experiments showed both the reversible and irreversible changes of disc mechanical properties following fatigue loading.

The outcome of biologic structure (e.g., spine) after fatigue loading was complicated and difficult to compare among different researches. It was because the type and loading condition of fatigue loading were not consis- 
tently defined. Differentiating type of fatigue loading may help synthesize experimental results. Two types of fatigue loading were categorized in engineering material tests, i.e., the high cycle fatigue and the low cycle fatigue. The high cycle fatigue was defined as high cycle number with mild loading magnitude, whereas the low cycle fatigue was defined as low cycle number with large loading magnitude. In the study of spine biomechanics, there is less discussion about the high cycle and low cycle fatigue loading. Nevertheless, the type of fatigue loading may be roughly categorized by the purpose of simulation. For example, the high cycle fatigue may simulate the loading during a vibratory environment without excessive bearing [e.g., $260 \mathrm{~N}$ (mean) for 86,400 cycles $^{36}$ ]. The low cycle fatigue may simulate the loading during repetitive lifting with mild to heavy weight [e.g., $3 \mathrm{Nm}$ for 9000 cycles, ${ }^{37} 500-3150 \mathrm{~N}$, for 8253, 3257, and 263 cycles at $0,22.5$, and 45 degree flexion, ${ }^{38,39} 1472 \mathrm{~N}$ (mean) for 6000 cycles, ${ }^{32}$ and $3076 \mathrm{~N}$ (mean) for 9600 cycles $^{40}$ ]. The loading magnitude of this study was fixed at $425 \mathrm{~N}$ (mean), hence the 2 hours (36,000 cycles) fatigue loading may be attributed to the high cycle fatigue loading.

The disc stiffness of current study (ranged from 800 to $1000 \mathrm{~N} / \mathrm{mm}$ ) is lower than the range of human lumbar disc $(3660 \mathrm{~N} / \mathrm{mm}$, test environment: $30 \mathrm{~Hz}$, free vibration with $400 \mathrm{~N}$ surrogate), ${ }^{35}$ and human cervical disc stiffness $(4000 \mathrm{~N} / \mathrm{mm}$, test environment: $400 \mathrm{~N}, 10 \mathrm{~Hz}$, $31.4 \mathrm{~mm} / \mathrm{s}) .{ }^{41}$ The disc damping coefficient of current study (ranged from 0.4 to $0.7 \mathrm{Ns} / \mathrm{mm}$ ) is a little bit higher than the range of human lumbar disc $(0.3 \mathrm{Ns} / \mathrm{mm}$, test environment: $30 \mathrm{~Hz}$, free vibration with $400 \mathrm{~N}$ surrogate). ${ }^{35}$ The reason that the stiffness of porcine disc is lower than the human disc may be due to the anatomic or the physiologic condition of disc. The porcine spine is analogue to human spine in terms of anatomic, geometric, and functional characteristics. ${ }^{36,42}$ Because the size of porcine lumbar disc is close to the human lumbar disc and smaller than the human cervical disc, the effect of geometrical differentiation on the dynamic properties between human and porcine disc may be minimal. The tested specimen was from 6-month-old swine, and the physiologic condition of specimen was close to the one of young human adult. The soft stiffness of porcine disc may be largely due to the highly hydration content of healthy disc. The results of current study may be similar to the results of human healthy disc, but different from the human degenerated disc.

In conclusion, the dynamic properties of intervertebral disc depend on the degree of disc hydration and integrity. During the short-term fatigue loading, the fatigue loading squeeze out the fluid within the disc, and attenuate the disc properties. After the rehydration, the disc properties can be recovered to the original status. During the long-term loading, the fatigue loading not only squeeze the fluid out, but also may have damaged the disc integrity. Therefore, although the disc properties recovered to the original status after rest because of the rehydration, the rate of attenuation disc properties dur- ing the second fatigue loading is faster than the one during first fatigue loading because of the damaged disc.

\section{- Key Points}

- The compressive stiffness of healthy porcine lumbar intervertebral disc is 781 (SD: 58) N/mm, and the damping coefficient is 0.65 (SD: 0.08 ) Ns/mm. The damping ratio of disc with $9 \mathrm{~kg}$ surrogate is 0.123 (SD: 0.015).

- The stiffness of disc increased, but the damping coefficient of disc and damping ratio of disc construct (i.e., disc with surrogate) decreased with the fatigue loading.

- A 12-hours saline bath rest following a shortterm fatigue loading $(0.5$ hours at $5 \mathrm{~Hz})$ can fully restore the disc dynamic properties.

- A 12-hours saline bath rest following a longterm fatigue loading ( 2 hours at $5 \mathrm{~Hz}$ ) can also restore the disc dynamic properties to the original condition. However, the degradation of disc dynamic properties during the subsequent fatigue loading was faster than the previous fatigue loading.

- Rest cannot always recover the dynamic properties of fatigue-loaded intervertebral disc. It depends on the degree of fatigue loading.

\section{Acknowledgment}

Graduate students, Ke-Yong Wang, Chun-Kai Chaing, Chia-Chun Hsu, Ya-Wen Kuo, and Wang-Chu Chen helped building the testing apparatus.

\section{References}

1. Marras WS, Lavender SA, Leurgans SE, et al. Biomechanical risk factors for occupationally related low back disorders. Ergonomics 1995;38:377-410.

2. Marras WS, Parakkat J, Chany AM, et al. Spine loading as a function of lift frequency, exposure duration, and work experience. Clin Biomech (Bristol, Avon) 2006;21:345-52.

3. Kumar S. Cumulative load as a risk factor for back pain. Spine 1990;15: 1311-16.

4. Wilder DG, Pope MH. Epidemiological and aetiological aspects of low back pain in vibration environments - an update. Clin Biomech (Bristol, Avon) 1996;11:61-73.

5. Kumar A, Varghese M, Mohan D, et al. Effect of whole-body vibration on the low back. A study of tractor-driving farmers in north India. Spine 1999; 24:2506-15.

6. Liu YK, Njus G, Buckwalter J, et al. Fatigue response of lumbar intervertebral joints under axial cyclic loading. Spine 1983;8:857-65.

7. Hansson TH, Keller TS, Spengler DM. Mechanical behavior of the human lumbar spine. II. Fatigue strength during dynamic compressive loading. J Orthop Res 1987;5:479-87.

8. Adams MA, Hutton WC. Gradual disc prolapse. Spine 1985;10:524-31.

9. Liu YK, Goel VK, Dejong A, et al. Torsional fatigue of the lumbar intervertebral joints. Spine 1985;10:894-900.

10. Kelsey JL, Githens PB, Walter SD, et al. An epidemiological study of acute prolapsed cervical intervertebral disc. J Bone Joint Surg Am 1984;66: 907-14.

11. Kelsey JL, Githens PB, White AA III, et al. An epidemiologic study of lifting and twisting on the job and risk for acute prolapsed lumbar intervertebral disc. J Orthop Res 1984;2:61-6.

12. Lafferty JF, Winter WG, Gambaro SA. Fatigue characteristics of posterior elements of vertebrae. J Bone Joint Surg Am 1977;59:154-8. 
13. Tsantrizos A, Ito K, Aebi M, et al. Internal strains in healthy and degenerated lumbar intervertebral discs. Spine 2005;30:2129-37.

14. Zhao F, Pollintine P, Hole BD, et al. Discogenic origins of spinal instability. Spine 2005;30:2621-30.

15. Pollintine $\mathrm{P}$, Dolan $\mathrm{P}$, Tobias JH, et al. Intervertebral disc degeneration can lead to "stress-shielding" of the anterior vertebral body: a cause of osteoporotic vertebral fracture? Spine 2004;29:774-82.

16. Pollintine P, Findlay G, Adams MA. Intradiscal electrothermal therapy can alter compressive stress distributions inside degenerated intervertebral discs. Spine 2005;30:E134-9.

17. Lee CK, Kim YE, Lee CS, et al. Impact response of the intervertebral disc in a finite-element model. Spine 2000;25:2431-9.

18. Ekstrom L, Kaigle A, Hult E, et al. Intervertebral disc response to cyclic loading-an animal model. Proc Inst Mech Eng [H] 1996;210:249-58.

19. Johannessen W, Vresilovic EJ, Wright AC, et al. Intervertebral disc mechanics are restored following cyclic loading and unloaded recovery. Ann Biomed Eng 2004;32:70-6.

20. van der Veen AJ, Mullender M, Smit TH, et al. Flow-related mechanics of the intervertebral disc: the validity of an in vitro model. Spine 2005;30:E534-9.

21. Vresilovic EJ, Johannessen W, Elliott DM. Disc mechanics with transendplate partial nucleotomy are not fully restored following cyclic compressive loading and unloaded recovery. J Biomech Eng 2006;128:823-9.

22. van der Veen AJ, van Dieen JH, Nadort A, et al. Intervertebral disc recovery after dynamic or static loading in vitro: is there a role for the endplate? J Biomech 2007;40:2230-5.

23. MacLean JJ, Owen JP, Iatridis JC. Role of endplates in contributing to compression behaviors of motion segments and intervertebral discs. J Biomech 2007;40:55-63.

24. Galante JO. Tensile properties of the human lumbar annulus fibrosus. Acta Orthop Scand 1967:( suppl 100):1-91.

25. Chanchairujira K, Chung CB, Kim JY, et al. Intervertebral disk calcification of the spine in an elderly population: radiographic prevalence, location, and distribution and correlation with spinal degeneration. Radiology 2004;230: 499-503.

26. Pfirrmann CW, Metzdorf A, Elfering A, et al. Effect of aging and degeneration on disc volume and shape: A quantitative study in asymptomatic volunteers. J Orthop Res 2006;24:1086-94.

27. Panjabi MM, Goel V, Oxland T, et al. Human lumbar vertebrae. Quantitative three-dimensional anatomy. Spine 1992;17:299-306.

28. Wang JL, Lee YL. The shock attenuation properties of straight standing knee joint using different shock absorbers and energy input. J Chin Inst Eng 2003;26:729-36.

29. Gatt CJ Jr, Hosea TM, Palumbo RC, et al. Impact loading of the lumbar spine during football blocking. Am J Sports Med 1997;25:317-21.

30. Cholewicki J, McGill SM, Norman RW. Lumbar spine loads during the lifting of extremely heavy weights. Med Sci Sports Exerc 1991;23:1179-86.

31. Essendrop M, Trojel Hye-Knudsen C, Skotte J, et al. Fast development of high intra-abdominal pressure when a trained participant is exposed to heavy, sudden trunk loads. Spine 2004;29:94-9.

32. Aultman CD, Scannell J, McGill SM. The direction of progressive herniation in porcine spine motion segments is influenced by the orientation of the bending axis. Clin Biomech (Bristol, Avon) 2005;20:126-9.

33. Thomson WT, Dahleh MD. Theory of Vibration with Applications. 5th ed. New Jersey: Prentice Hall; 1998.

34. Malko JA, Hutton WC, Fajman WA. An in vivo magnetic resonance imaging study of changes in the volume (and fluid content) of the lumbar intervertebral discs during a simulated diurnal load cycle. Spine 1999;24:1015-22.

35. Izambert O, Mitton D, Thourot M, et al. Dynamic stiffness and damping of human intervertebral disc using axial oscillatory displacement under a free mass system. Eur Spine J 2003;12:562-6.

36. Callaghan JP, McGill SM. Intervertebral disc herniation: studies on a porcine model exposed to highly repetitive flexion/extension motion with compressive force. Clin Biomech (Bristol, Avon) 2001;16:28-37.

37. Goel VK, Voo LM, Weinstein JN, et al. Response of the ligamentous lumbar spine to cyclic bending loads. Spine 1988;13:294-300.

38. Gallagher S, Marras WS, Litsky AS, et al. An exploratory study of loading and morphometric factors associated with specific failure modes in fatigue testing of lumbar motion segments. Clin Biomech (Bristol, Avon) 2006;21: 228-34.

39. Gallagher S, Marras WS, Litsky AS, et al. Torso flexion loads and the fatigue failure of human lumbosacral motion segments. Spine 2005;30:2265-73.

40. Adams MA, Hutton WC. The effect of fatigue on the lumbar intervertebral disc. J Bone Joint Surg Br 1983;65:199-203.

41. Dahl MC, Rouleau JP, Papadopoulos S, et al. Dynamic characteristics of the intact, fused, and prosthetic-replaced cervical disk. J Biomech Eng 2006; 128:809-14.

42. McLain RF, Yerby SA, Moseley TA. Comparative morphometry of L4 vertebrae: comparison of large animal models for the human lumbar spine. Spine 2002;27:E200-6. 